\title{
Desindustrialização e degradação socioambiental
}

\author{
Por Marcel Bursztyn, Melissa Curi, Gabriela Litre, Carlos Hiroo Saito
}

doi:10.18472/SustDeb.v10n1.2019.24269

No contexto do reordenamento econômico mundial das últimas décadas, a questão ambiental assume um papel de crescente relevância, como fator adicional nas ponderações dos custos e dos benefícios financeiros das estratégias globais de mercado. Desde o final da Segunda Guerra Mundial, o mundo seguiu uma tendência que, de certo modo, rompia com o determinismo da teoria econômica clássica.

O padrão histórico, por cerca de dois séculos, estabelecia uma divisão de trabalho entre os países, onde alguns poucos teriam potencialidades para se industrializar e muitos seriam produtores de bens primários (minerais ou agropecuários). Entretanto, estratégias nacionais permitiram o surgimento de importantes polos industriais nos chamados países periféricos. Mão de obra mais barata, mercados internos atraentes e disponibilidade de recursos naturais e fontes de energia redesenharam a distribuição da produção de manufaturas pelo mundo.

Em alguns países, a industrialização teve papel de destaque na dinâmica da economia interna e no balanço do comércio exterior. Abria-se uma oportunidade de rompimento com o padrão herdado do sistema colonial, por meio da agregação de valor aos recursos naturais. Na América Latina, Brasil, México e Argentina, principalmente, apresentavam uma crescente participação do setor industrial no conjunto dos seus respectivos produtos internos brutos.

Cinquenta anos depois, entretanto, os mesmos países passam por processos de desindustrialização relativa. Ou seja, a indústria cresce menos (e em alguns setores diminui) do que os setores de serviços e primário (agropecuária e extração mineral).

Sob o ponto de vista geopolítico, trata-se de uma certa volta a um regime de trocas semelhante ao período colonial, já que o preço das commodities é regido por regras que obedecem muito mais aos movimentos dos mercados globais do que aos custos efetivos da produção, em cada local.

Em termos políticos e institucionais, abre-se um amplo espaço às elites-geralmente conservadoras - associadas ao agronegócio e à mineração, em detrimento de setores mais modernos da sociedade. Inevitavelmente, seus lobbies adquirem poder de pressão por decisões políticas e normativas de seu interesse. Politicamente, trata-se de uma subserviência ao mercado global. Ambientalmente, trata-se de reviver o passado em que o ambientalismo nascente representava um obstáculo ingênuo e desnecessário ao crescimento da nação e ao livre enriquecimento de seus agentes econômicos.

Vista pela ótica ambiental, essa tendência é portadora de consequências preocupantes. Como a formação dos preços de mercado é ditada por forças externas ao processo (e aos custos) de produção, o resultado é uma pressão sobreas duas categorias de fatores que podem ser sobreexploradas. A primeira é o trabalho, que tende a não usufruir monetariamente aos ganhos de produtividade e que, muitas vezes, sequer usufrui dos direitos da legislação trabalhista e previdenciária. A segunda é o meio natural, já que há uma intensificação da extração de recursos renováveis e não renováveis e, principalmente, os custos da degradação (do solo, das florestas, dos recursos hídricos, da contaminação em geral) não são considerados no preço final dos produtos. 
No primeiro caso, trata-se de dumping social; no segundo, de dumping ambiental, entendendo-se o conceito de dumping como uma situação em que um produto é vendido por um preço abaixo do seu custo real de produção.

Diante de tal situação, a revista Sustentabilidade em Debate convidou o Professor Pierre Salama, conhecido economista especializado em América Latina da Universidade de Paris 13, para analisar os fundamentos econômicos desse processo e suas implicações sociais e ambientais.Desde a década de 1960, Salama desenvolve pesquisas sobre os principais movimentos do capital e as relações de trabalho. No Brasil, dentre outras obras, publicou Economia em decomposição $e$ Dolarização: ensaio sobre a moeda, industrialização.

Conforme anunciado no Editorial anterior, SeD, com apoio da FAP-DF, vem implementando o seu processo de internacionalização. Na seção Varia do presente número, além dos artigos em português, temos um artigo em francês, três artigos em inglês e dois artigos em espanhol. Para novas submissões, conforme as regras da revista que passaram a vigorar no dia primeiro de janeiro do ano em curso, lembramos aos autores da exigência de pagamento da taxa de submissão e da tradução do artigo submetido em português para o inglês, caso ele seja aceito para publicação na revista.

O primeiro artigo, de autoria do Professor Pierre Salama, com o título Amérique Latine: good-bye industrie, hello stagnation (Latin America: good-bye industry, hello stagnation) tem como objetivos levantar os efeitos da industrialização sobre o emprego e a distribuição de renda na América Latina e analisar as condições para que esses países deixem de perder a revolução industrial em curso.

$\mathrm{O}$ artigo Facing food security and climate change adaptation in semi-arid regions: lessons from the Brazilian Food Acquisition Program (Enfrentando a segurança alimentar e a adaptação às mudanças climáticas em regiões semiáridas: lições do Programa Brasileiro de Aquisição de Alimentos), das autoras Patrícia Mesquita e Carolina Milhorance, faz uma análise sobre o Programa Brasileiro de Aquisição de Alimentos (PAA) dentro de um contexto de seca extrema na região do Cariri, estado do Ceará, Brasil. As limitações que impedem toda a gama de benefícios potenciais do PAA, assim como o levantamento de possíveis medidas para promover impactos positivos aos beneficiários são considerados a partir da percepção dos atores institucionais envolvidos com o programa.

Os autores Ana Paula Martins do Amaral Cunha et al., no artigo The challenges of Consolidation of a Drought-Related Disaster Risk Warning System to Brazil (Desafios para a Consolidação de um Sistema de Alerta de Risco de Desastre Associado às Secas no Brasil), apresentam os desafios para a consolidação de um sistema de alerta de risco de desastres associados às secas no Brasil e propõem uma estrutura inicial de atribuição de responsabilidades entre as instituições nacionais envolvidas com a temática para guiar ações de mitigação dos riscos.

Ainda sobre a temática das mudanças climáticas, o artigo Subnational Climate Policies: a proposal for monitoring in Rio Grande do Sul, Brazil (Políticas Climáticas Subnacionais: uma proposta de monitoramento no Rio Grande do Sul, Brasil), do autor Markus Erwin Brose, propõe a adoção de ferramenta de monitoramento de iniciativas climáticas, desenvolvida pela rede Open Climate Network, para acompanhamento da política sobre mudanças climáticas no estado do Rio Grande do Sul. Para tanto, considerou as principais iniciativas de mitigação e adaptação climática no estado entre os anos de 2011 e 2017.

O artigo Salvaguardas da Redd: proteção para as comunidades da Caatinga em Pernambuco, Brasil, dos autores Afonso Feitosa Reis Neto, Maria do Socorro de Araújo e Everardo Sampaio, com base na metodologia Redd Safeguard Spectrum Framework (RSS Framework), faz uma análise das salvaguardas propostas para implementação da Redução do Desmatamento e da Degradação Florestal (Redd) na Caatinga de Pernambuco.

Os autores Daniela Del Castillho et al., no artigo ¿Qué lugar ocupan actores sociales em el contexto de servicios ecosistémicos? Una revisión en áreas de ecología y biología de La conservación (Que lugar ocupam os atores sociais no contexto dos services ecossistêmicos? Uma revisão nas áreas de ecologia e conservação biológica), apresentam uma revisão de artigos científicos focados 
em serviços ecossistêmicos, publicados entre 2005-2017, para investigar de que maneira eles recuperam vozes de diferentes atores sociais.

A autora Erika Saccucci, no artigo Estudio de la significación de la inseguridad ambiental en dos casos en Córdoba, Argentina (Estudo da significação da insegurança ambiental em dois casos em Córdoba, Argentina), considerando contextos dicrusivos e de relação de poder, apresenta um estudo sobre o significado da poluição em dois conflitos articulados em torno a questão ambiental: Pueblos Unidos e VUDAS - Vizinhos Unidos em defesa de um ambiente seguro em Córdoba, Argentina.

No artigo Sustentabilidade e escolhas alimentares: por uma biografia ambiental dos alimentos, os autores Ana Luísa Araujo de Oliveira, Fabiana Thomé da Cruz e Sergio Schneider discutem sobre as características do sistema agroalimentar contemporâneo e fazem uma reflexão sobre o uso da abordagem biográfica como referencial teórico para analisar relações entre os alimentos e o ambiente.

Por fim, o artigo Análise de reciclabilidade de armações de óculos solares: policarbonato vs madeira, dos autores Manuela Kanan et al., tem como proposta analisar o final do ciclo de vida desse produto. Para tanto, elaborou-se um questionário virtual, obtendo-se 765 respostas, eforam realizadas entrevistas em óticas, lojas especializadas e oficinas de reparos da cidade de Porto Alegre, estado do Rio Grande do Sul, Brasil.

Desejamos uma ótima leitura!

\section{Os Editores}

